\title{
Efficiency of Metal Plaque Lubricants in Bearing Supports of Machinery for Public Utilities and Services
}

\author{
Vasily Gennadievich Zharov \\ Russian State University of Tourism and Service, Moscow, Russia
}

\begin{abstract}
This work analyzes the efficiency of metal plaque lubricants in bearing supports of machinery for public utilities and services at the stage of assembling and maintenance.

The ways to improve performances of plastic lubricants are presented. Advantages and disadvantages of metal plaque plastic lubricants for friction unit of machinery for public utilities and services are discussed.

Necessity of correct selection of metal plaque additives at the stages of assembling and maintenance of units and respective advantages are described depending on interaction of friction couples aiming at improvement of operation lifetime of machinery for public utilities and services.

Based on experimental results of Russian and foreign researchers, including this work, a composite lubricant was proposed on the basis of TsIATIM-201 lubricant with MKF-18 additive in the concentration of $0.0075 \mathrm{wt} \%$. The experimental results have demonstrated that the tribotechnical properties of the proposed composite lubricant are superior to those of basic lubricant in combination with widely applied additives.

Under conditions of high and extra high loads, metal compounds are more preferable as metal plaque additives, whereas under normal loads, these are powdered metals. Among disadvantages of these additives, it is possible to mention the lack of stability of tribotechnical properties in wide load range: these properties are the most obvious under the action of either low or high loads.
\end{abstract}

Key words: plastic lubricants, frictional interaction, metal plaque additives, fillers, friction unit, bearings.

\section{INTRODUCTION}

Numerous utility machinery items and equipment are used by public utility companies, such as washers-extractors, pumps, dry-cleaning and washing machines, other machines and units.

According to information by servicing companies, $24.9 \%$ of all faults of washers-extractors are caused by damages of bearing units of washing drum.
Complicated mechanical and physicochemical phenomena occur during operation in the area of interaction of washer-extractor bearings under the influence of various factors, such as lubricating medium, material of friction couples, type of interaction, resulting in variation of mechanical properties of conjugated surfaces $[1,2]$. Wearing of bearing supports of washing drum results in increased noises and vibration during operation as well as increased power consumption due to increase in friction coefficient and other factors [3].

At the stage of unit assembling, lubricant (TsIATIM-201, TsIATIM-203, TsIATIM-221, LITOL-24) is charged into bearings and is not replaced during operation, since it is related with significant time consumptions during repair and the use of integral designs of washing drums made of polymer materials.

Monitoring of technical state of bearing supports of washers-extractors is difficult because operators sometimes cannot detect faulty conditions at initial stage which sufficiently quickly reaches the stage of critical wear [4, 5].

Operability loss of bearing unit leads to extended downtime of washers-extractors accompanied by significant expenses.

Dry-cleaning and washing companies operate with numerous types of machinery and equipment, their efficient use depends on operation lifetime which depends on operability of bearing support of inner drum shaft $[2,6]$.

Analysis of faults of dry-cleaning and washing machines, according to information from servicing companies, has demonstrated that the most frequent faults occur with bearings of inner drum shaft, equaling to $46.4 \%$ of total faults of dry-cleaning machines [2, 7].

Operation lifetime of bearing support of inner drum of dry-cleaning and washing machines largely depends on operation conditions, loads during operation, contact with aggressive liquids, such as perchloroethylene, trichloroethylene or white spirit $[1,6]$.

Overall operability of this equipment depends on faultless operation of bearing supports. Operability loss of bearing unit reduces efficient operation time of equipment, vibration increases, noise level during operation rises, power consumption increases. Forced downtimes related with repair, recovery or replacement of worn parts lead to additional expenses. 
Operation conditions of bearing supports of washers-extractors and utility machinery are similar for all considered types of equipment and characterized by application of roller bearings of the same sizes, similar lubricants and lubricating conditions, they are exposed to loads of similar direction and value.

Aiming at development of measures to increase lifetime of bearing supports of this equipment, it is necessary to perform detailed analysis of factors influencing their operability.

Wide application of roller bearings in washers-extractors, dry-cleaning and washing machines, utility machinery and other industries resulted in significant increase in production of antifriction lubricants together with new requirements in comparison with those applied to plain bearings. Contrary to the effect observed in sliding friction, the friction coefficient in roller bearings with flooded lubrication increases instead of decrease. The role of lubricant in roller bearings is comprised mainly of protection of friction surfaces against wear, scoring, and corrosion, which is better provided by plastic lubricants in comparison with wet lubricants [8,9].

Most friction units lubricated by plastic lubricants are referred to roller bearings. The peculiarity of lubrication of the friction units is that only minor portion of plastic lubricant is in the working and reserve areas $[8,10]$, the remaining portion is ballast. It remains steady and does not participate directly in lubrication. Frequent replacement of lubricant allows to increase significantly the lifetime of bearings; however, in most cases this is related with shutdown, disassembling and downtimes of machinery. In addition, designs of some bearing units do not involve frequent replacement and supply of lubricant during operation as already mentioned.

In comparison with oils, the lubricants are characterized by certain advantages:

- good retention on inclined and even vertical surfaces;

- no squeezing from friction units under significant loads;

- lower variation of viscosity with temperature;

- better performances of antifriction and anti-scoring properties;

- better protection of metal surfaces against ambient impacts;

- high sealing of friction units;

- more reliable and efficient operation under severe operation conditions upon simultaneous action of high temperatures, variable speeds, etc.;

- cost efficient application due to more extended lubricating ability, lower consumption and maintenance costs.

Disadvantages of plastic lubricants include the lack of heat removal from treated parts, more complicated supply system of plastic lubricant to friction unit, and low resistance of soap greases against oxidation [8, 9].

In the simplest and somewhat idealized case, the lubricants can be considered as two-component systems comprised of liquid base: dispersion medium, and solid thickener: dispersion phase. Synthetic, petroleum oil and other wet lubricant are used as dispersion medium (75-95 wt \% of lubricant). Dispersion phase (5-25\%) can be comprised of high-molecular carboxylic salts: soaps, solid hydrocarbons, inorganic (highly dispersed silica gel, bentonites, lyophilic graphite, etc.) and organic (carbon black, pigments, polymers, urea derivatives, etc.) materials, as well as other highly dispersed substances with well-developed specific surface area capable to form structure in anhydrous mediums. Such two-component system can include only lubricants based on polysiloxanes thickened by carbon black, pigments, and polymers. In all other cases, in addition to dispersion medium and dispersion phase, the lubricant should include the third or even the fourth component. This component could be obligatory, otherwise plastic lubricant does not exist as structured system, or this component is included as technological one [11].

The necessity to improve quality of additives is dictated by restricted conditions of their application (increase in temperatures, loads, velocities of friction units) and general strengthening of requirements to reliability and endurance of machinery and mechanisms, mainly bearings.

While analyzing the works $[1,8,10,12]$, it is possible to state that one of the main engineering and chemical approaches to improvement of performances of numerous plastic lubricants is addition of various additives and fillers.

Additives are considered as the third component of lubricants. Additives are surfactants and this predetermines their activity both in the bulk of lubricant and on thickener/dispersion medium interface. They influence significantly the formation of structural frame of soap greases and are not dispersion phase. Fillers should be considered as a constituent of dispersion phase of lubricants, in fact, they do not have any effect on structure formation. The main and basic difference between additives and fillers is their solubility in petroleum and other oils: dispersion mediums of lubricants [11].

Using additives or filler in lubricants, it is possible not only to improve this or that performance of their quality but also to obtain systems retaining colloidal structure and stability for a long time, which depends not only on additive concentration but is also determined by conditions of production process. Based on the results in [9], it is possible to state that the action of additives in lubricants and especially of admixtures, together with direct positive functions, improvement of lubricating and protection ability or resistance against oxidation, can be accompanied by negative impact on the structure and certain performances of lubricants. It is demonstrated in the work that weakening of lubricants by surfactants is the most dangerous, since lubricants and most of colloidal systems are quite sensitive to the action of even minor amounts of surfactants $(0.05-0.1 \%)$.

Thus, it is required to optimize selection of composition and concentration of additives so that the secondary effect of their action both on the structure and performances would be minimum. 
Another component of lubricants improving their properties are fillers. Fillers or solid additives are highly dispersed oil-insoluble materials, which do not form colloidal structure in lubricants but comprise independent dispersion phase and improve performances [1,13].

High lubricating ability, chemical and thermal resistance are the main reasons to use fillers as additives to lubricants operating in heavy loaded friction units and under other severe conditions [11].

The fillers for plastic lubricants are mainly comprised of layered crystalline substances characterized by low-friction coefficients: molybdenum disulfide and diselenide, graphite, mica, talcum, boron nitrite, vermiculite, sulfides of certain metals, and other materials. In addition, solid high polymers are used, containing bound halide atoms, polytetrafluoroethylene (PTFE), metal oxides, powdered metals. Let us consider in more details the action of the most popular fillers to lubricants.

Molybdenum sulfide due to its good lubricating properties is widely applied in fabrication of lubricants, in particular as antifriction additive to plastic lubricants. However, under the action of hydrogen, which is always present on the area of fiction contact, molybdenum is reduced to metal. In order to reduce corroding action of MoS2, dispergation is accompanied by addition of amines, phenolates and carboxylates of alkaline metals or zinc. Good thickeners are petroleum and synthetic oils, which form structured systems: lubricants characterized by superior elastic viscous, anti-wear and anti-scoring properties [11].

Graphite is characterized by low friction coefficient, extremely easy polishability, fatness, and plasticity. Graphite is used as antifriction additive in fabrication of lubricants [9]. Due to wide availability and relatively low cost, graphite is widely used in lubricants.

Polymerization products of various compounds depending on initial raw stock, method of their production, and final properties are used as dispersion medium in fabrication of lubricants, some of them are used as thickeners: dispersion phase, and some of them as viscous or adhesive additives. Some polymers can be used as fillers improving lubricating performance $[9,13]$.

The most efficient polymer fillers, which improve significantly lubricating performance, are powdered polytetrafluoroethylene (PTFE) produced in accordance with State standard GOST 10007-80 known as ftoroplast-4, several grades, and in accordance with Substandard OST 6-05-402-80 known as ftoroplast-40, also several grades. Fillers also can be presented by polytrifluoroethylene, polychlorotrifluoroethylene, and others.

Fluoroplactics and other halogen derivatives of polyethylene are characterized by high thermal stability, resistance against aggressive mediums, good low-temperature properties. They not only improve anti-scoring and anti-wear properties of lubricants but also improve significantly their lubricating performance.
When powdered polyethylene and polypropylene are added to lubricants below polymer point $\left(60-90^{\circ} \mathrm{C}\right)$, they act as fillers improving antifriction properties of lubricants. Such fillers are used in lubricants with the upper limit of operability not exceeding $120^{\circ} \mathrm{C}$.

Metal oxides and powdered metals are widely used as fillers $[9,10,13]$. They are introduced not only to improve anti-scoring and anti-wear properties or to prevent pitting but also for the purpose of electric conductivity. However, they also have some disadvantages.

The use of these fillers, especially of powdered metals, is efficient during sliding friction and harmful during rolling friction. Highly dispersed powders of lead and copper catalyze oxidation; lead is toxic, other metals while contacting with free alkali in soap greases displace hydrogen. It is rather difficult to distribute all powdered metals in the bulk of lubricant, thus, specialized hardware is required for fabrication of such lubricants, fineness of powdered metals should not exceed 10-15 $\mu \mathrm{m}$ [14]. Dispersed metal particles settle with time and at high sliding velocities are separated from overall lubricant system.

The most common fillers in the field of metal oxides and powdered metals are zinc oxide, titanium oxide, powdered aluminum, copper, lead, tin, bronze, brass, which are added to ready lubricants by mixing in amounts from 1 to 5\%, sometimes $15-30 \%$. The mentioned powders are produced on commercial scale in Russia.

Upon addition of dispersed metal particles into plastic lubricants, such as TsIATIM-201, TsIATIM-203, it is possible to clad metal surface of friction couples, to reduce friction by an order of magnitude and temperature by $20-30^{\circ} \mathrm{C}$, thus increasing significantly operation lifetime.

Application of metal plaque lubricants with the aim of increase in lifetime of bearing supports of washers-extractors and utility machinery is an urgent issue.

In order to select optimum material and its concentration in lubricant, it is required to study the influence of operation factors, such as contact load, number of loading cycles of friction couple and slipping, on wear, deformation and pitting of materials of bearing supports of the mentioned machinery.

\section{METHODS}

The studies of bearing supports aiming at obtaining of reliable information about their operation lifetime, reliability, and operability should be based on laboratory, bench, and commercial tests. Experimental equipment should simulate operation of actual unit concerning such parameters and factors as constituent materials, quality of their surface, lubricating medium, lubricating conditions, contact pressure, speed of rolling (sliding), slipping, etc. Design of equipment and its accessories should provide monitoring of operation conditions and measurements of main variables with required accuracy. 
Taking into consideration all aforementioned requirements, the contact fatigue of materials was tested using a SMTs-2 machine for studies of friction, wear, and destruction of surfaces upon rolling friction (with and without slipping) and sliding with and without lubricant [15]. The machine can operate according to the following flowcharts: 1 ) with closed kinematic circuit at fixed slipping coefficient; 2) with open kinematic circuit when one sample is fixed.

In order to test contact fatigue, let use the flowchart with closed kinematic circuit at fixed slipping coefficient allowing simulation of operation of actual roller bearing.

Figure 1 illustrates kinematic flowchart of the machine using samples of disc-roller type. The lower sample, the roller 5, is rotated by the electric motor 1 with $\mathrm{V}$-belt drive, replaceable pulleys and by the gears $\mathrm{Z} 0-\mathrm{Z1}$, and the upper sample, the disc 4 , - by the gears Z0 - Z2 and replaceable couple Z3 - Z4 which is used for adjustment of preset slipping coefficient. The upper sample, the disc 4, is pressed against the lower sample, the roller 5 , by rotation of the equalizing carrier 2 around the $\mathrm{Z} 2-\mathrm{Z} 3$ axis by means of the spring assembly 3 . The load is adjusted using the scale. The friction moment is measured by the contactless inductive meter 6 , and the rotation frequency of the sample 5 is measured by electric counter. The friction moment is recorded on diagram chart of electron potentiometer located together with frequency meter in special cabinet.

The rotation frequency of leading sample, the roller 5 , is 300 , 500 , and 1,000 min-1; the slipping coefficient is $0,10,15,20$, 100 ; the load on samples is $200 \ldots 2,000 \mathrm{~N}$ (in closed kinematic circuit); the measurement error of load is $5 \%$; the maximum friction moment is $15 \mathrm{Nm}$; the measurement error of friction moment is $5 \%$.

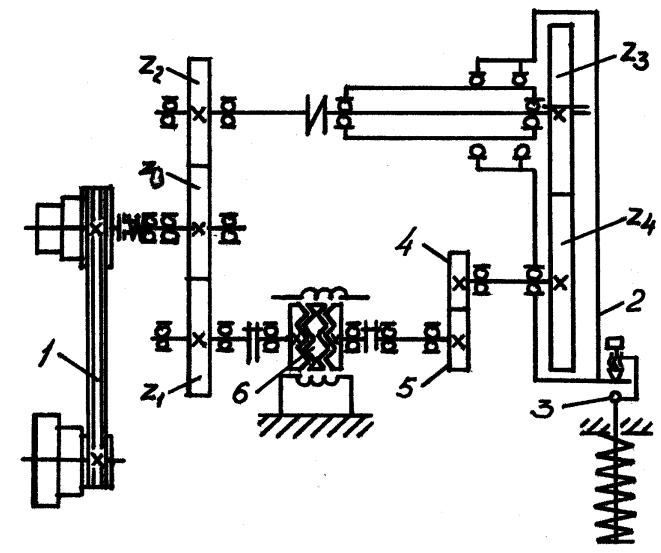

Figure 1: Kinematic flowchart of SMTs-2 friction, wear, and endurance testing machine

The peculiar feature of these studies is that the variations (deformation) of roller surface should be considered strictly along the path of contact with disc (deforming element). Therefore, in the considered case it is impossible to apply regular procedures of wear measurement (slot cutting, imprint method, etc.); it is required to measure variation of linear size of sample without violation of contact path, that is, without disassembling of the tested unit.

Thus, the friction testing machine [16] was modified by installation of measurement unit of residual deformations (Fig 2), comprised of a rack and a dial test indicator with the measurement accuracy of $\pm 0.0025 \mathrm{~mm}$.

This unit makes it possible to eliminate (decrease) measurement error of wear during repeated measurements. In order to lubricate the considered samples, the SMTs-2 machine was additionally equipped with lubricating unit.

The tests were performed as follows. At first, the samples were prepared (Fig. 3). The roller (deformed sample) was made of ball bearing steel, grade ShKh15, and thermally treated to HRC 51...53; the disc (deforming sample) was made of ball bearing steel, grade ShKh15, and thermally treated to HRC $61 \ldots 63$.

Prior to the tests, the samples were marked on nonworking edge surface by punch; at the same time three marks were applied over $120^{\circ}$ onto external side of edge surface. Then the samples were installed into the SMTs- 2 machine according to the flowchart (Fig. 1); lubricant supply onto sample surface was verified by sample rotation by $360^{\circ}$. The considered surface was analyzed using the dial test indicator adjusted with tension of $0.2 \mathrm{~mm}$. Zero on the indicator was set on the basis of average of three measurements; the angular velocity of deforming sample, the disc, the slipping and the contact load were preset.

The samples were tested with lubrication of deformation area by TsIATIM-201 plastic lubricant. After certain time intervals corresponding to 1,000 cycles (from 0 to 10,000 cycles), 10,000 cycles (from 10,000 to 100,000 cycles), and 100,000 cycles (more than 100,000 cycles), the tests were terminated, the deformed path was measured to determine the degree of deformation in three preset points (using the marks applied onto the surface of deformed sample).

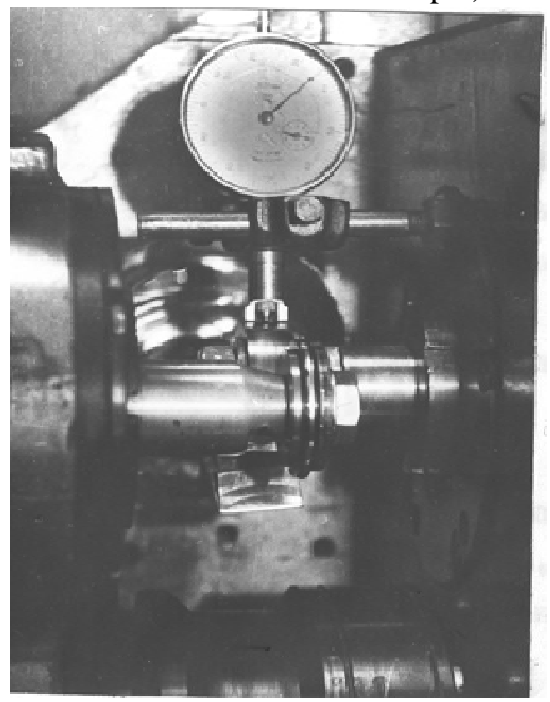

Figure 2: General view of residual deformation measuring unit 


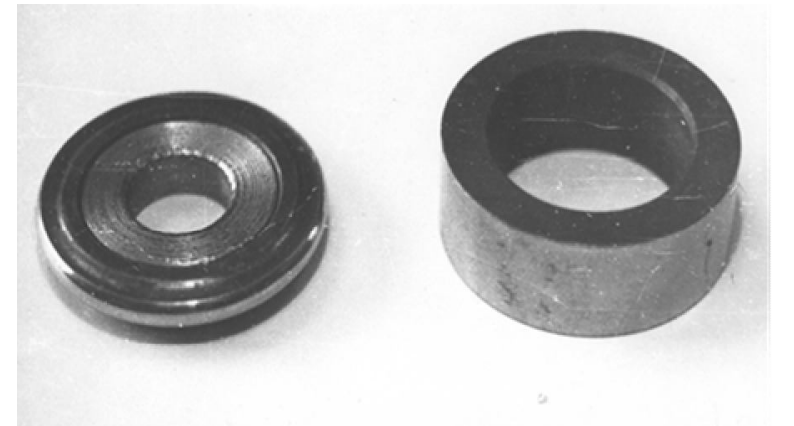

Figure 3: General view of samples for contact endurance testing

Variation of the path size (deformation degree) was determined as the average of three measurements. At the same time the path was visually inspected to determine initiation of pitting. Occurrence of pittings characterizes initiation of fatal destruction of surfaces; in the considered case, this is ultimate state of material characterizing operation lifetime (contact endurance) [8, 17, 18]. After occurrence of pittings with the sizes up to $0.25 \mathrm{~mm} 2$, the tests were terminated.

\section{RESULTS}

TsIATIM-201 was selected as basic plastic lubricant, and MKF-18 concentrated copper containing additive was used as metal plaque material in preliminary tests.

Formation of protective metal coating on contacting surfaces is affected by radial load, degree of slipping (friction provides conditions for cleaning of surface from oxides and creation of juvenile reactive surface), as well as by interaction time.

In the works of Russian scientists devoted to modern additives to lubricants, including plastic ones, it is stated [6, 12, 18-20] that concentration of plaque elements in lubricants is from $0.05 \mathrm{wt} \%$ for industrial oils to $0.2 \mathrm{wt} \%$ for greases. It is also known that for plastic lubricants, higher contents of metal plaque materials are required [20-23].

In the case of preliminary studies, it was adopted that the range of working concentrations of MKF-18 additives in greases was from 0.05 to $0.2 \mathrm{wt} \%$.

The wear intensity Ih can be used as the target function upon determination of rational concentrations. In some works [12, $18,20,21,24]$, it was demonstrated that the wear intensity Ih of interacting materials as a function of plaque material was extreme and characterized by definite minimum. In the considered case, the function $\mathrm{Ih}=\mathrm{f}(\mathrm{C})$, obviously, will contain extreme; the experimental design $\mathrm{n} 1$ can be used in this case, that is, one parameter will vary at $n$ levels. The concentration of plaque material varied in the range from 0 to 0.2 wt $\%$ with the increment of $\Delta=0.05$ wt $\%$.

The experimental studies of lubricants based on TsIATIM-201 with additives studied and recommended by Russian scientists, namely: molybdenum disulfide (MoS2), molybdenum disulfide + fluorinated carbon, grade A $(\mathrm{MoS} 2+$ FC A), graphite $(G)$, were performed in the following mode: contact load $\mathrm{P}=1,000 \mathrm{~N}$, rotation frequency of leading sample $\mathrm{n}=300 \mathrm{~min}-1$, slipping coefficient $\mathrm{S}=1(100 \%$ slipping).

A roller made of steel, grade $\operatorname{ShKh} 15$ (HRC 51...53), and a shoe made of steel, grade ShKh15 (HRC 61...63), were used as samples.

The comparative results of composite lubricants are summarized in Table 1.

Table 1:Comparisons of composite lubricants

\begin{tabular}{|l|l|l|l|}
\hline Additive & $\begin{array}{l}\text { Concentratio } \\
\text { n of additives } \\
C, \text { wt } \% .\end{array}$ & $\begin{array}{l}\text { Wear, } \mu \mathrm{m}, \\
\text { per } \\
N=10 * 10^{5} \\
\text { loading } \\
\text { cycles }\end{array}$ & $\begin{array}{l}\text { Wear } \\
\text { intensity } I_{h} \\
, \mu \mathrm{m} / \mathrm{h}\end{array}$ \\
\hline MKF-18 & $\mathbf{0 . 0 7 5}$ & $\mathbf{5 7}$ & $\mathbf{0 . 1 0}$ \\
\hline Basic lubricant & 2.0 & 82 & 0,16 \\
\hline $\mathrm{MoS}_{2}$ & 81 & 0.18 \\
\hline $\mathrm{MoS}_{2}+$ FC A & $2.0+8.0$ & 73 & 0.16 \\
\hline $\mathrm{G}$ & 5.0 & 94 & 0.22 \\
\hline
\end{tabular}

It can be seen that the proposed composite lubricant is characterized by superior tribotechnical properties in comparison with the basic lubricant and materials with widely applied additives [25].

\section{DISCUSSION}

As shown above, operation lifetime of bearings upon lubrication by metal plaque compositions under conditions of friction interaction and surface plastic deformation depends first of all on the concentration $\mathrm{C}$ of metal plaque material in grease.

Evdokimov and Levinski performed detailed studies aimed at selection of optimum additives to plastic lubricants. These researchers have established that increase in content of powdered copper in lubricant in excess of certain amount leads to increase in the temperature of friction unit and impairment of anti-scoring properties of lubricant. Restriction of content of powdered copper in plastic lubricants should be based on specific operation conditions of friction couples. Similar results were obtained in the case of addition of cuprous oxide and glycerol to lubricants.

It has been established that addition of certain powdered soft metals provides better effect than additions of constituent alloys [26]. According to the experimental data by Evdokimov and Levinski, it follows that additions of tin-lead-bismuth and tin-lead-cadmium powdered alloys to lubricants increase significantly loading capacity of friction couple and decrease its temperature. However, the latter alloy has low melting point $\left(94^{\circ} \mathrm{C}\right)$, which in the case of severe friction modes leads to its melting and deposition. In addition, 
optimum amount of tin-lead-cadmium powdered alloy is $2-5 \%$, and for tin-lead-bismuth it equals to $5-20 \%$. These powdered metals are characterized by the same disadvantages as powdered copper.

Kuzharov, Onishchuk, and Suchkov [27] studied lubricants based on LITA composition with additions of powdered copper, copper (II) acetylacetonate, and complex forming additive: acetylacetone. Herewith, compositions of acetylacetone with powdered copper and acetylacetone with copper acetylacetonate were studied. The obtained compositions were compared with the base, LITA plastic lubricant, and LITA containing acetylacetone.

The experimental results evidence that addition of metal plaque components to plastic lubricant improves both antifriction and anti-wear properties. Herewith, addition of powdered copper or copper acetylacetonate provides approximately the same effect, the friction coefficient decreases by about $10 \%$ and wear resistance increases by $2-3$ times. Additional doping of the considered compositions with acetylacetone improves significantly their tribotechnical properties. The friction coefficient decreases by 1.5-2 times in comparison with the base, and wear resistance increases more than 10 times. In the case of composition with copper acetylacetonate and acetylacetone, the sizes of friction bodies increase, which is peculiar for friction in the mode of wearlessness [20] and is related with formation of servovite film on friction surface.

However, the studies have revealed different action of the considered metal plaque additives, which is attributed to the fact that the additives react differently to ambient conditions, in particular, to energy intensity of friction contact, which in the considered experiments is directly related with load. Under low loads, copper acetylacetonate does not provide formation of metal plaque film because energy conditions on friction contact are insufficient for decomposition of the complex and copper deposition on conjugated surfaces, and under sufficiently severe loads, the energy of friction interaction exceeds activation barrier of tribo-restorative decomposition of the complex.

Let consider another possible method of lubrication of friction couples of steel-steel with metal plaque additives, based on plasticizing of metal surface layer (Rehbinder effect), which makes significant contribution to lubrication $[13,28]$ and is especially obvious upon contact regarding chemical essence and phase structure [2, 28].

Copper containing film should exert strong plasticizing action on steel surface as the film of any other soft metal. However, contrary to liquid surfactants and corrosion active mediums, it can initiate selective plasticization exclusively in the places of its actual contact with steel, that is, without weakening of material subsurface layers. Thus, in [29] the data are reported about ten-fold decrease in roughness of steel surface after friction with TsIATIM-203 lubricant with powdered copper and complex forming substance $(\mathrm{Ra}=0.075$ $\mu \mathrm{m})$ in comparison with the surface roughness after operation with TsIATIM-203 lubricant without additives $(\mathrm{Ra}=0.7$ $\mu \mathrm{m})$. In laboratory tests, the friction coefficient in these lubricants was 0.074 and 0.098 , respectively. It has been established that the friction coefficients for steel and copper are approximately the same equaling to 1.2 , whereas for steel coated with copper, it equals to 0.4 .

Denisova N., Denisova L., Gontar, Kivshenko, Svishchevskaya [30] performed studies using plastic lubricants: TsIATIM-202, TsIATIM-201, 1-13, LITOL-24, solid oils, etc. in roller bearings of machines of textile and light industry and concluded that the parts interacted with each other only in comparatively small area, i.e., the sites of actual contact were exerted to high stresses, plastic deformation appeared, as well as mutual intrusion of contacting elements and intensive wear [23].

The researchers in [30] performed pilot tests of SMP-5 metal plaque lubricant with PMS-2 copper powder in amount of $6 \%$ and surfactants: $0.25 \%$ glycerol and $0.25 \%$ oleic acid. The tests demonstrated that the use of metal plaque lubricant made it possible to increase lifetime of friction units by at least two times, to decrease friction loss to $30 \%$, to increase lifetime of lubricant before refilling or replacement by at least two times, to decrease consumption of lubricants and consumption of electricity to $20 \%$.

While studying friction surfaces of rollers and roller paths, it has been established that the friction surfaces contain copper spots or colonies of small spots with the sizes from $0.01 \mathrm{~mm}$ to $0.001 \mathrm{~mm}$ and even lower. Herewith, the friction surfaces of bearings show specific glow of copper spots, which demonstrates the absence of oxidation. However, this method of application of protective antifriction coating does not allow to provide film of equal thickness, existence of numerous lubricating components complicates technology of its production. Application of fine copper powder is related with the difficulties during uniform distribution of powder in overall bulk of lubricant, with the increase in the friction coefficient at high thickness of coating; in the case of significant heating of lubricant, powdered copper can settle onto the bottom of oil casing. Triboengineering properties of plastic copper containing lubricants depend on performances of basic lubricant and the essence of contacting materials [31].

In [32] the influence of addition of metal plaque additive to lubricant on contact strength of steel was studied. The contact strength tests were performed using two-roller machine. The samples were made of steel, grade 40X. The samples were exposed to bulk hardening to $35 . . .36 \mathrm{HRC}$ (advanced roller) and to $41 \ldots 45 \mathrm{HRC}$ (dragging roller). Operation mode was rolling with forced slipping. The samples were tested until formation of pittings with the sizes of $0.5 \ldots 0.6 \mathrm{~mm}$. The lubricant was industrial oil, grade 20, and industrial oil, grade $20+0.1 \%$ metal plaque additive comprised of copper (I) oleate $(50 \%)$ and oleic acid (50\%). This additive upon sliding 
friction decreased wear intensity of steel and cast iron parts by $2 . . .5$ times and improved anti-scoring properties of steel surfaces. It dissolved well in lubricating oil and other hydrocarbon liquids at $40 \ldots 60^{\circ} \mathrm{C}$.

The experiments demonstrated that at high contact compression stresses, no differences were observed in contact strength of samples lubricated with regular oil and the oil with metal plaque additive. At lower loads (600...700 MPa), there was significant increase in the contact strength of samples lubricated with oil with metal plaque additive. The samples survived twice as much cycles $\mathrm{N}$.

It was assumed in [24] that during the contact strength tests of samples upon lubricating by oil with metal plaque additive, formation of copper film should lead to decrease in contact stress, i.e., to increase in strength. However, in [32] the content of metal plaque additive was low $(0.1 \%)$ and could not provide formation of sufficient copper layer, which would be able to decrease stresses. At such concentration of additive under conditions of sliding friction of steel against steel, the copper layer cannot be visually observed [23, 33].

Aiming at increase in wear resistance of friction units of textile machinery using selective transfer, the lubricant was used on the basis of I-20A industrial oil with MKF-18 concentrated copper containing additive (Specification TU-38.101127-87). The researchers performed several tests to determine optimum concentrations of the additive in lubricant depending on material of friction couple. On the basis of the experimental results [34], it should be mentioned that for all considered couples, the additive concentrations in oil, which provided minimum wear intensity, were in the range of $0.10 \ldots 0.20 \mathrm{wt} \%$. The researchers did not detect significant decrease in friction coefficient for overall range of MKF-18 concentration.

The obtained experimental results agree with the existing concepts of selective transfer, which is the most efficient in heavy loaded friction units $[24,35]$. This could be attributed to the fact that at increased loads, the friction surfaces are exerted to plastic deformation which promotes mechanical activation of surface layers, removal of oxide films preventing formation of protective film. In addition, under conditions of plastic deformation, the Rehbinder effect manifests itself most completely, providing decrease in strength of thin surface layers. Metal film with the thickness of $0.5 \ldots 1 \mu \mathrm{m}$ increases actual contact area by $1.5 \ldots 2$ times [32] decreasing, respectively, working loads. Herewith, the interval before occurrence of initial signs of fatigue flaking sharply increases. The influence of metal plaque lubricants on selective transfer upon friction was studied in [21]. The tests were performed using roller-shoe flowchart according to the procedure in [12]. Several comparative tests were carried out with materials of normalized and quenched steels, grades 45 and 40X. Solid oil Zh, TsIATIM-201, TsIATIM-221, and LITOL-24 were used as basic lubricants, and concentrated copper containing MKF-18 was used as additive.
Optimum concentration of additive was determined for provision of minimum wear intensity. For the considered variants, it was in the range of $0.10-0.15 \mathrm{wt} \%$. The load before sticking upon stepwise loading increased by at least five times. Stabilization time (running-in time) decreased to $25 \ldots 40 \mathrm{~min}$. Wear intensity of friction couples at loads equaling to $80 \%$ of sticking load in the case of lubricants with MKF-18 decreased by $8 \ldots 10$ times. At the same time certain decrease in friction force and temperature was observed. At loads equaling to $50 \%$ of sticking load, the wear intensity decreased by $5 \ldots 7$ times. Operation time of friction couple without renewal of lubricant, as determined by violation of steady mode, increased by $3 . . .4$ times.

\section{CONCLUSION}

Application of metal plaque lubricants in friction units provides formation of extremely thin (at the level of atoms) protective metal film on working surfaces, this film is self-restored upon friction interaction of parts.

In order to initiate selective transfer, it is recommended to add concentrated copper containing additive (developed by Russian State University of Tourism and Services Studies) by the weight of lubricant.

The concentrated copper containing additive is the 50\% solution of copper containing product in I20A basic oil, it is intended for decrease in friction loss and wear. The additive is homogeneous dark green liquid with the flash point not lower than $180^{\circ} \mathrm{C}$ and the solidification point not higher than $-9^{\circ} \mathrm{C}$. The concentrated copper containing additive should be introduced into plastic lubricant as follows:

- to prepare $10 \%$ solution of the additive in LITOL-24, TsIATIM - 201 (or another plastic lubricant), this is performed by addition of required amount of the additive at $20-40{ }^{\circ} \mathrm{C}$ to the required amount of lubricant and mixing until homogeneous state using a mechanic stirrer or rubbing through fine screen (mesh size up to $0.2 \mathrm{~mm}$ ) several times;

- in order to obtain the additive concentration by weight of LITOL, TsIATIM- 201 (or other plastic lubricant), it is necessary to mix one weight portion of $10 \%$ solution of the additive with sixty four weight portions of pure plastic lubricant.

The pure lubricant should be added stepwise, thoroughly mixing it by mechanical stirrer or rubbing through sieve until production of homogenous composition.

It would be reasonable to use the proposed plastic composite lubricant in bearing units of washer-extractor and other household equipment in combination with other measures aimed at improvement of operation lifetime of machinery based on the effect of metal plaque plating: pre-operational running of units in metal plaque mediums, final antifriction non-abrasive processing of working surfaces in metal plaque media, and others $[6,12,23,36]$.

In bearing supports of inner drum of washers-extractors, it 
would be reasonable to use packing seals impregnated with metal plaque materials.

In order to use the obtained experimental results, recommendations were developed to improve operation lifetime of washers-extractors and utility machinery by means of metal plaque plating, including household drum washing machines intended for automated washing, rinsing, extracting and drying under stationary conditions at the temperature of water and cleansing solution from 0 to $90^{\circ} \mathrm{C}$, as well as machinery operating under stationary conditions at the temperatures from 0 to $85^{\circ} \mathrm{C}$ with substances similar to pure water in terms of density, viscosity, and chemical activity; herewith, the circulating liquids should not contain mechanical impurities in amount of $0.1 \mathrm{vol} \%$ and with the sizes more than $0.2 \mathrm{~mm}$.

In order to improve their operation lifetimes, the methods of metal plaque plating are proposed allowing to form friction surfaces with high hydrogen wear resistance at all operation stages: during preparation for operation by final antifriction non-abrasive processing in metal plaque working mediums; during operation and maintenance by means of metal plaque lubricants.

It could be concluded that certain types of metal plaque lubricants and appropriate additives should be selected with consideration for conditions of friction interaction. Under high and extra high loads, metal compounds as metal plaque additives are preferable, and in the range of moderate loads, it is recommended to use powdered metals. In addition, in both cases the lubricants should contain components (complex forming additives) providing metal transfer from one surface to another and formation of film defect structure. Among disadvantages of these additives, it is possible to mention the lack of stability of tribotechnical properties in wide load range: these properties are the most obvious under the action of either low or high loads. The thickness of servovite film is not the same in different places of friction surface, which could lead to adhesion. Application of film is influenced significantly by external factors, preparation of lubricant should include thorough mixing in order to provide homogeneous distribution of additives in overall lubricant [25].

\section{REFERENCES}

1. V.N. Bystrov, I.E. Pashkovskii, M.E. Stavrovskii, B.V. Voronin. Povyshenie iznosostoikosti uzlov treniya oborudovaniya predpriyatii bytovogo obsluzhivaniya, rabotayushchikh $\mathbf{v}$ agressivnykh sredakh [Improvement of wear resistance of friction units of public utilities equipemnt operating in aggressive mediums]. In: Issues of improvement of public utility machinery, 58, pp. 60-62, 1985.

2. V.G. Zharov, L.V. Sumzina, A.V. Maksimov. Analiz konstruktsii podshipnikovykh opor tekhnologicheskogo oborudovaniya servisnykh predpriyatii [Analysis of bearing support designs for technological equipment of servicing companies]. Promyshlennyi servis, 2(67), pp. 37-39, 2018.

3. E.V. Pavlova, A.A. Silayeva, O.N. Borisova, I.G. Doronkina, A.P. Sokolova. Analysis of the world and Russian E-commerce market: Development trends and challenges. International Journal of Engineering and Technology(UAE), 7(4), pp. 387-392, 2018. https://doi.org/10.14419/ijet.v7i4.38.24588

4. S.V. Shaytura, M.D. Knyazeva, V.M. Feoktistova, T.A. Vintova, V.A. Titov, Y.P. Kozhaev. Philosophy of information fields. International Journal of Civil Engineering and Technology, 9(13), pp. 127-136, 2018.

5. S.V. Shaytura, Y.P. Kozhaev, K.V. Ordov, T.A. Vintova, A.M. Minitaeva, V.M. Feoktistova. Geoinformation services in a spatial economy. International Journal of Civil Engineering and Technology, 9(2), pp. 829-841, 2018.

6. I.E. Pashkovskii, M.E. Stavrovskii, V.A. Bardin. Opredelenie optimal'noi kontsentratsii metalloplakiruyushchikh komponentov po pereraspredeleniyu vodoroda $\mathrm{v}$ sisteme uzla treniya [Determination of optimum concentration of metal plaque components by redistribution of hydrogen on friction unit]. In: Advanced technologies and researches in the field of service. Moscow: MGUS, p. 192, 1999.

7. I.E. Pashkovskii. Improvement of lifetime of bearing supports of washer-extractor by engineering methods. Moscow, 1990.

8. V.G. Zharov, L.V. Sumzina, A.V. Maksimov. Vliyanie sostava plastichnogo smazochnogo materiala na ekspluatatsionnye kharakteristiki podshipnikovykh opor mashin i oborudovaniya kommunal'nogo khozyaistva i servisnykh predpriyatii [The influence of composition of plastic lubricant on performances of bearing supports of public utility machinery]. Promyshlennyi servis, 3(68), pp. 22-26, 2018.

9. R.M. Matveevskii, V.L. Lashkhi, I.A. Buyanovskii, I.G. Fuks, K.M. Badyshtova. Smazochnye materialy. Antifriktsionnye i protivoiznosnye svoistva. Metody ispytanii [Lubricants. Antifriction and antiwear properties. testing methods]. Moscow: Mashinostroenie, 1989.

10. K.I. Klimov. Antifriktsionnye plastichnye smazki [Antifriction plastic lubricants]. Moscow: Khimiya, 1988.

11. Yu.L. Ishchuk. Tekhnologiya plastichnykh smazok [Technology of plastic lubricants]. Kiev: Naukova dumka, 1986.

12. A.K. Prokopenko. Izbiratel'nyi perenos $\mathbf{v}$ uzlakh treniya mashin bytovogo naznacheniya [Selective transfer in friction units of utility machinery]. Moscow: Legprombytizdat, 1987.

13. I.G. Fuks. Dobavki k plastichnym smazkam [Additives to lubricants]. Moscow: Khimiya, 1982. 
14. Yu.A. Radin, P.G. Suslov. Bezyznosnost' detalei mashin pri trenii [Wearlessness of machine parts upon friction]. Leningrad: Mashinostroenie, 1989.

15. V.V. Klyuev. Ispytatel'naya tekhnika [Testing machinery]: Reference book. Moscow: Mashinostroenie, 1982.

16. V.G. Zharov, P.V. Golovkin, T.A. Shestopalov. Modernizatsiya mashiny SMTs-2 dlya ispytanii materialov na trenie i iznos [Modernization of SMTs-2 friction and wear testing machine]. In: New materials and technologies. New craft technologies. Proceedings; 7th International conference "Science to industry of service". State University of Tourism and Services Studies, p. 39, 2002.

17. N.B. Demkin, E.V. Ryzhov. Kachestvo poverkhnosti i kontakt detalei mashin [Surface quality and contact between machine parts]. Moscow: Mashinostroenie, 1981.

18. I.E. Pashkovskii, V.G. Zharov, V.V. Nashivochnikov, I.N. Bestaev. Eksperimental'noe opredelenie parametrov tekhnologicheskogo protsessa obrabotki stal'nykh detalei $v$ metalloplakiruyushchikh sredakh [Experimental determination of processing variables of steel parts in metal plaque mediums]. In: New materials and technologies in the field of service. Collection of scientific works. Moscow: MGUS, pp. 50-52, 2000.

19. I.N. Bestaev, A.V. Nikishin, P.V. Golovkin, I.E. Pashkovskii. Razrabotka i issledovanie sposoba poverkhnostnogo plasticheskogo deformirovaniya stal'nykh detalei v metalloplakiruyushchikh sredakh [Development and analysis of plastic deformation of steel parts in metal plaque mediums] In: New materials and technologies in the field of service. Collection of scientific works. Moscow: MGUS, Proceedings of 2nd International conference: Industry of service in the 21st century, pp. 50-52, 2000.

20. 20. 4. D.N. Garkunov. Tribotekhnika (iznos i bezyznosnost') [Triboengineering (wear and wearlessness] Guidebook, 4th edition, revised and supplemented. Moscow: MSKhA, 2001.

21. B.G. Zhigailo. Ispol'zovanie plastichnykh smazochnykh materialov pri rabote uzlov $v$ rezhime izbiratel'nogo perenosa [Plastic lubrication during operation in selective transfer mode]. In: Improvement of lifetime of public utilities machinery on the basis of tribological engineering MTI, pp. 28-34, 1989.

22. I.E. Pashkovskii, V.G. Zharov. Issledovanie vliyaniya sostava plastichnogo smazochnogo materiala na kontaktnuyu vynoslivost' podshipnikovykh stalei [The influence of composition of plastic lubricant on contact endurance of bearing steels]. In: New materials and technologies. New craft technologies. Proceedings; 7th International conference "Science to industry of service". State University of Tourism and Services Studies, pp. 37-38, 2002.
23. A.K. Prokopenko. Improvement of lifetime of friction parts and tools of consumer and utility industry during operation. Moscow, 2000.

24. D.N. Garkunov. Izbiratel'nyi perenos v tyazhelonagruzhennykh uzlakh treniya [Selective transfer in heavy loaded friction units]. Moscow: Mashinostroenie, 1982.

25. Yu.I. Archakov. Sovremennye problemy zashchity metallov ot vodorodnoi korrozii [Modern Issues of protection of metals against hydrogen corrosion]. Fiziko-khimicheskaya mekhanika materialov, 3, pp. 15-20, 1986.

26. V.D. Evdokimov, V.L. Levinskii. Primenenie novykh smazochnykh materialov dlya povysheniya iznosostoikosti detalei mashin [Application new lubricants for improvement of wear resistance of machine parts]. Endurance of machine friction parts. Issue 2. Mashinostroenie, pp. 70-74, 1987.

27. A.S. Kuzharov, N.Yu. Onishchuk, V.V. Suchkov. Vliyanie med'soderzhashchikh dobavok na tribotekhnicheskie svoistva plastichnoi smazki LITA [The influence of copper containing additive on tribotechnical properties of LITA plastic lubricant]. Trenie i iznos, 10(5), pp. 903-908, 1989.

28. P.A. Rebinder, E.D. Shchukin. Poverkhnostnye yavleniya $v$ tvyordykh telakh $v$ protsessakh ikh deformatsii i razrusheniya [Surface phenomena in solids during their deformation and destruction]. Uspekhi fizicheskikh nauk, 108(1), pp. 3-42, 1972. https://doi.org/10.3367/UFNr.0108.197209a.0003

29. A.S. Kuzharov, V.V. Suchkov. Obrazovanie koordinatsionnykh soedinenii na trushchikhsya poverkhnostyakh par - med'-med' v srede salitsilal'alanina [Formation of coordinating compounds on friction surface of copper-copper couples in salicyl alanine]. Zhurnal fizicheskoi khimii, 54(12), pp. 3114-3117, 1980.

30. N.E. Denisova, I.N. Gontar', A.M. Kivshenko, G.I. Svishchevskaya, L.E. Denisova. Opyt primeneniya metalloplakiruyushchei smazki v podshipnikakh tekstil'nykh mashin [Application of metal plaque lubricants in bearings of textile machines]. In : Endurance of machine friction parts. Issue 4. Mashinostroenie, pp. 29-34, 1990.

31. A.P. Gribailo. Vliyanie med'soderzhashchikh plastichnykh smazochnykh materialov na tribologicheskie kharakteristiki [The influence of copper containing plastic lubricants on tribological properties]. In: Endurance of machine friction parts, 4. Mashinostroenie, pp. 130-138, 1990.

32. E.A. Panfilov. Kontaktnaya ustalost' stali pri smazyvanii obraztsov maslom s metalloplakiruyushchei prisadkoi [Contact fatigue of steel upon lubrication with metal plaque additive]. In: Lifetime of machine friction parts]. Mashinostroenie, 1, pp. 72-74, 1986. 
33. V.A. Suchilin, L.V. Sumzina, A.V. Maksimov. Method for Refrigerators Efficiency Increasing. IOP Conference Series: Materials Science and Engineering, 262 (1), 2017.

https://doi.org/10.1088/1757-899X/262/1/012121

34. V.N. Frantsev, N.G. Kozhaeva, A.N. Kot. Povyshenie sroka sluzhby detalei trikotazhnykh mashin primeneniem metalloplakiruyushchego smazochnogo materiala [Improvement of lifetime of textile machines by metal plaque lubricant]. Collection of works: Improvement of operation lifetime of utility machinery on the basis of triboengineering. Moscow: MTI, 1989.

35. A. Demenev, A. Naberezhnykh. Research of the process of formation of noise in Household Refrigerators. Akustika, 32, pp. 135-137, 2019.

36. Wear resistance. Wear resistance of machinery and instruments on the basis of structural adaptability of materials. Structural, engineering, and operational methods and tools of adjustment of surface strength upon friction: Recommendations. Kiev: UkrTsSM, 1985. 